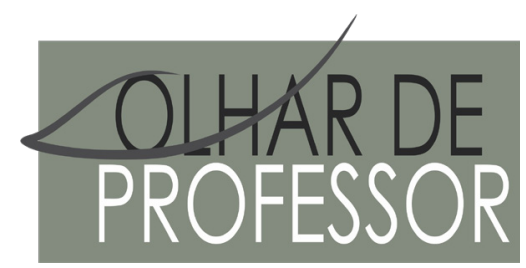

DOI: 10.5212/OLHARPROFR.V.23.2020.15813.209209225983.0604

\title{
LUGARES DA MULHER NA LITERATURA INFANTO-JUVENIL: ANÁLISE DE LIVROS QUE PROPÕEM UMA DISCUSSÃO DO PAPEL DA MULHER NA SOCIEDADE DE MANEIRA NÃO ESTEREOTIPADA
}

\author{
PLACES OF WOMEN IN CHILDREN'S LITERATURE: ANALYSIS OF BOOKS THAT PROPOSE A DISCUSSION OF \\ THE ROLE OF WOMEN IN SOCIETY IN A NON-STEREOTYPED WAY
}

\author{
EL LUGAR DE LA MUJER EN LA LITERATURA INFANTIL: ANÁLISIS DE LIBROS QUE PROPONEN UNA \\ DISCUSIÓN DEL PAPEL DE LA MUJER EN LA SOCIEDAD DE MANERA NO ESTEREOTIPADA
}

MARCO ANTONIO BETTINE DE ALMEIDA*

OLIVIA RALL**

\begin{abstract}
Resumo: Ao problematizar o discurso presente em livros infanto-juvenis a partir de um olhar feminista, baseado em Linda Nicholson, Joan Scott, Guacira Lopes Louro e Paulo Freire pretende-se debater as maneiras como são representadas as mulheres na literatura, bem como os demais âmbitos sociais que as contemplam ou não, como: família, trabalho, política. Acreditando que as identidades advêm de relações construídas social e discursivamente, busca-se tematizar para desconstruir conceitos que ainda são tidos como naturais. Com o objetivo de que professores possam partir dos livros analisados para incitar os estudantes a enxergarem os personagens e o enredo por outro panorama, de modo a visar a possibilidade de emancipação do pensamento por parte de todos os envolvidos no processo educacional. Os resultados serão apresentados pelas categorias: Empoderamento Feminino, Participação Política, Identidade, A Mulher Emancipada e os Contos de Fadas. Visamos auxiliar professores e quem mais se propor a fazer uma leitura com o propósito de engrandecer o olhar da criança para as diferenças.
\end{abstract}

Palavras-chave: Literatura infanto-juvenil. Mulher. Questão de gênero.

\begin{abstract}
Problematizing the discourse present in children's books from a feminist perspective, based on Linda Nicholson, Joan Scott, Guacira Lopes Louro and Paulo Freire, it is intended to debate how women are represented in the literature, as well as the other social areas that contemplate them or not, such as: family, work, politics. Believing that identities come from socially constructed relationships and discursively, we seek to contribute to deconstruct concepts that still being as natural. The aim is to encourage teachers, starting from the books analyzed, to encourage students to see the characters and the plot brought by the story from another perspective, aiming at the possibility of emancipation of all those involved in the educational process. The results obtained so far will be presented by categories: Female empowerment, Political Participation, Identity, Emancipated woman and fairy tales. The goal is to assist teachers and those who propose to do a reading with the purpose of magnifying the child's gaze for differences.
\end{abstract}

Keywords: Children's literature. Woman. Gender issues.

Resumen: Al problematizar el discurso presente en los libros infantiles desde un punto de vista feminista, basado en Linda Nicholson, Joan Scott, Guacira Lopes Louro y Paulo Freire se pretende un debate sobre las formas en que las mujeres están representadas en la literatura, así como las demás esferas sociales que las contemplan o no,

\footnotetext{
* Professor Pós-Doutor e Coordenador do Programa Interdisciplinar de Pós-Graduação em Mudança Social e Participação Política (USP). E-mail: marcobettine@usp.br

${ }^{* *}$ Mestra em Ciências pelo Programa Interdisciplinar de Pós-Graduação em Mudança Social e Participação Política (USP2020), Pedagoga (UNESP-2009) e Professora do Ensino Fundamental pela Rede Municipal de Guarulhos (SP). E-mail: oli. oliviarall@gmail.com
} 
tales como: familia, trabajo, política. Creyendo que las identidades provienen de relaciones construidas social y discursivamente, buscamos contribuir a deconstruir conceptos que aún tienen el peso cultural de los naturales. Con el objetivo de que los docentes puedan partir de los libros analizados para animar a los alumnos a ver los personajes y la trama que trae la historia desde otra perspectiva, con el fin de apuntar a posibilidad de emancipación del pensamiento por parte de todos los implicados en el proceso educativo. Los resultados obtenidos se presentarán por categorías: Empoderamiento femenino, Participación política, Identidad, La mujer emancipada y los cuentos de hadas. Con esto, nuestro objetivo es ayudar a los profesores y cualquier otra persona que se proponga a hacer una lectura para mejorar la visión del niño de las diferencias.

Palabras-clave: Literatura infantil y juvenil. Mujer. Problema de género.

\section{INTRODUÇ̄̃̃O'}

Esse trabalho tem como objetivo problematizar a literatura infanto-juvenil como reforçadora de um binarismo das questões de gênero. Busca-se ressaltar a importância do debate e do pensamento crítico como o defendido por Paulo Freire em prol de uma educação verdadeiramente transformadora. Ideia essa reforçada pela autora bell hooks² em seu livro O feminismo é para todo mundo - políticas arrebatadoras (2019), no qual afirma: “A literatura infantil é um dos locais cruciais para a educação feminista, para a conscientização crítica, exatamente porque crenças e identidades ainda estão sendo formadas” (2019, p. 46).

Ao estudar o discurso presente em livros infanto-juvenis a partir de um olhar feminista, pretende-se facilitar a aquisição de um olhar crítico para as maneiras como são representadas as mulheres na literatura. Ao pensar especificamente no contexto escolar, Veiga-Neto (2001, p.1) também nos evidencia que "a própria organização do currículo e da didática, na escola moderna, foi pensada e colocada em funcionamento para, entre várias outras coisas, fixar quem somos nós e quem são os outros”.

Mais do que questionar essa lógica dicotômica, é preciso historicizar essa polaridade e a hierarquia que ela implica. Pela visão de Skliar (1999, p. 22) “as oposições binárias supõem que o primeiro termo define a norma e que o segundo existe fora do domínio daquele”.

Um ponto muito importante nesse sentido, ressaltado por Pierre Bourdieu em seu livro que leva o nome de A dominação masculina (2019), é o de que “a visão androcêntrica impõe-se como neutra e não tem necessidade de se enunciar em discursos que visem legitimá-la. A ordem social funciona como uma imensa máquina simbólica que tende a ratificar a dominação masculina sobre a qual se alicerça” (2019, p. 24).

Precisamos de fato nos propor a pensar sobre quais são os “mecanismos históricos responsáveis pela des-historicização e pela eternização das estruturas da divisão sexual” (BOURDIEU, 2019, p. 8), e com isso começarmos a compreender que aquilo que historicamente nos parece eterno, nada mais é do que um produto de um trabalho de eternização feita pelas classes dominantes juntamente com instituições como a Família, a Igreja e a Escola.

Para Hall (2005) as identidades no mundo atual estão sendo descentradas; o sujeito que antes era visto como unificado, na pós-modernidade passa a ser heterogêneo e fragmentado. Fazendo-nos pensar, muitas vezes forçosamente, para além dos padrões sociais antes estipulados. Tem-se a chamada "crise de identidade” (HALL, 2005, p. 9) quando há uma “perda de um ‘sentido de si’ estável”. Quando há uma descentração do indivíduo, tanto de seu lugar no mundo social e cultural - raça, nação, religião - quanto de si mesmo - identidade de gênero, orientação sexual, ideologia - é que se põe em xeque a própria identidade.

\footnotetext{
${ }^{1}$ Agradecemos os pareceristas pela leitura cuidadosa que muito engrandeceram o trabalho, bem como a equipe editorial da revista.

${ }^{2} \mathrm{O}$ nome bell hooks é pseudônimo de Glória Jean Watkins em homenagem à sua bisavó materna e escreve-se com letras minúsculas porque a autora pretende dar enfoque à sua escrita e não à sua pessoa.
} 
No ambiente escolar essas múltiplas identidades convivem, às vezes de forma harmoniosa e outras vezes conflituosa, cabendo ao professor compreender o mundo heterogêneo e suas especificidades, e não mais buscar a homogeneidade como o ensino tradicional tanto nos instruiu.

\section{O QUEEE QUUESTÃO DE SALA DE AULA?}

Muito tem se falado sobre o que deve ou não ser abordado dentro do ambiente escolar. Temas como questões de gênero e pautas políticas têm aparecido como dúvidas se deveriam ou não fazer parte da demanda escolar. Na infância e na adolescência a escola é o maior ambiente de socialização do indivíduo. Fato esse que já deveria ser suficiente para que entendêssemos que assuntos do âmbito social surgirá de qualquer modo dentro do ambiente escolar.

Para compreendermos um desses pontos- a questão de gênero - é preciso ter em mente a história já vivida para que chegássemos até aqui. Foi na chamada segunda onda do movimento feminista, na década de 1960, que se colocou mais fortemente a discussão entre os termos gênero e sexo; uma vez que a palavra sexo passou a ser utilizada mais especificamente para se referir a diferenças biológicas entre corpos masculinos e femininos, enquanto gênero implicou reconhecer que há uma construção social que influencia essa concepção do que é feminino e do que é masculino, para além do que define o determinismo biológico (PLANTEL, 2016). Reconhecer isso implicou perceber que a sociedade e o modo como ela opera tem um grande papel no comportamento e na personalidade dos indivíduos, bem como na maneira como o corpo aparece nesse contexto social.

Louro em seu livro Gênero, sexualidade e educação (2011) faz o apontamento de que o gênero é constituinte de outro conceito complexo: o conceito de identidade. Por essa visão, "compreendemos os sujeitos como tendo identidades plurais, múltiplas; identidades que se transformam, que não são fixas ou permanentes, que podem, até mesmo, ser contraditórias” (2011, p. 24). Evidenciando, portanto, o caráter cultural e construído historicamente daquilo que é a identidade do indivíduo, e não algo pronto e acabado em sua definição.

Márcia Tiburi em seu livro Feminismo em comum, afirma:

Ninguém que tenha uma forma democrática de pensar e de sentir pode gostar de ser marcado ou de marcar o outro. As pessoas que não correspondem à ideia de heteronormatividade foram classificadas como gays, lésbicas, vadias, trans e outros nomes - dos quais depois vieram a se apropriar, como forma de usar a marcação sofrida para politizar a própria vida violentada pela ordem dominante (TIBURI, 2018, p 76).

A liberdade, pelas ideias defendidas por Paulo Freire [...] "é uma conquista e não uma doação. Exige uma permanente busca que só existe no ato responsável de quem a faz. Ninguém tem liberdade para ser livre: pelo contrário, luta por ela precisamente porque não a tem” (FREIRE, 1970, p.35).

De modo a descontruir os padrões sociais patriarcais ainda vigentes, o livro deve ser visto como um importante recurso a ser usado na Educação. Todos aqueles que já encontraram prazer na leitura e se influenciaram com a história de algum personagem, terão mais facilidade em reconhecer o livro como agente do processo de socialização. Tendo a literatura como aliada na transmissão de ideias e opiniões, é preciso (re)pensar quais os valores e os modelos de homem e mulher que os livros infanto-juvenis veiculam.

Rosemberg (1975, p.135) ressalta ainda a importância de questionarmos: "Em que medida os valores e os modelos comportamentais transmitidos nos livros estão de acordo com os objetivos educacionais vigentes? Tais valores e modelos acompanham a evolução da sociedade ou, ao contrário, permanecem estagnados em determinado momento histórico? ”.

Seguindo essa análise mais minuciosa dos padrões sociais nos livros, destaca-se também a representação familiar típica constituída por um pai, uma mãe e usualmente dois filhos, sendo um menino e uma menina, e representações estereotipadas de classe média e raça branca, como ocorre no livro "Feminina de menina, masculino de menino” em que há o predomínio da visão hegemônica de características relacionadas ao gênero e a perpetuação da visão binária de gênero. 
Quanto ao poder emancipatório contido na leitura, Petit (2008, p.19) sentencia:

Estou convencida de que a leitura, em particular a leitura de livros, pode ajudar os jovens a serem mais autônomos e não apenas objetos de discursos repressivos ou paternalistas. E que ela pode representar uma espécie de atalho que leva de uma intimidade um tanto rebelde à cidadania. [...] Gostaria de sensibilizá-los para a pluralidade do que está em jogo com a democratização da leitura entre os jovens.

A essa pluralidade da qual a autora nos fala é que queremos dar voz ao defender o acesso a livros que contenham visões de mundo heterogêneas e que fujam do discurso patriarcal recorrente em livros encontrados atualmente em salas de aulas, bibliotecas e residências. É preciso aprofundar os estudos sobre livros que tragam a imagem da mulher de um modo mais livre dos estereótipos conceituados na sociedade patriarcal, de modo a divulgá-los para professores e pais, e incentivá-los a usar os livros como uma ferramenta de desconstrução de paradigmas, visando promover a equidade de gênero e uma educação não sexista e não-discriminatória.

A preocupação com estereótipos de gênero é mais recente historicamente, e ainda há consideravelmente poucos títulos infanto-juvenis nacionais que trabalhem a figura feminina sob este olhar desconstruído. Sendo a mulher branca tradicionalmente retratada como sensível, frágil, mãe, esposa e dona de casa, e só mais recentemente podendo ser vista como uma mulher independente, forte, segura e independente. Precisamos ampliar as possibilidades acerca da imagem da mulher, favorecendo assim, a aceitação da diferença e proporcionando um novo olhar ao público ouvinte, ainda que inicialmente pelo breve momento em que a história é contada.

Com tudo o que foi exposto, pretende-se evidenciar que a escola, como ambiente formador de sujeitos e facilitador das relações interpessoais, deve se preocupar também com a maneira como essas trocas sociais acontecem e enxergar no livro um importante aliado no trabalho para desenvolver um currículo significativo que prepare seres humanos para a vida em sociedade e capacitados a pensar criticamente a realidade política, social e histórica da qual fazemos parte.

\section{MÉTODO DA PESQUISA}

Esta é uma pesquisa qualitativa e descritiva que utilizou a pesquisa dos livros infanto-juvenis para a coleta de dados. A pesquisa qualitativa estuda de forma integrada os fenômenos que envolvem as relações sociais, sendo privilegiada por permitir sua compreensão sob a perspectiva dos sujeitos envolvidos e no contexto em que ocorrem (CAVALCANTE; CALIXTO; PINHEIRO, 2014).

O método de apreciação e interpretação dos dados se deu pela Análise de Conteúdo, na perspectiva de Bardin (2011). Trata-se de um método de organização e análise de dados que visa qualificar fenômenos ou experiências, bem como as percepções dos sujeitos, ou determinados objetos.

A análise de conteúdo se constitui de várias técnicas na qual se busca descrever o conteúdo emitido no processo de comunicação, seja ele por meio de falas ou de textos; desta forma, a técnica é composta por procedimentos sistemáticos que proporcionam o levantamento de indicadores (categorias), permitindo a realização de inferência de conhecimentos (BARDIN, 2011).

Assim, a análise de conteúdo compreende técnicas de pesquisa que permitem, de forma sistemática, a descrição das mensagens e das atitudes atreladas ao contexto da enunciação, bem como as inferências sobre os dados coletados. A escolha deste método de análise pode ser explicada pela necessidade de ultrapassar as incertezas consequentes das hipóteses e pressupostos, pela necessidade de enriquecimento da leitura por meio da compreensão das significações e pela necessidade de desvelar as relações que se estabelecem além das falas propriamente ditas (CAVALCANTE; CALIXTO; PINHEIRO, 2014).

Para isso, analisamos vinte e um livros infanto-juvenis a partir da elaboração de quadros da seguinte maneira:

a) Um quadro geral dos livros analisados contendo todos os títulos e as palavras-chave que motivaram a pesquisa proposta; 
b) Um quadro específico para cada categoria sugerida: Empoderamento Feminino, Participação Política, Identidade, A Mulher Emancipada e os Contos de Fadas; e uma breve descrição da parte do livro que o enquadra na análise proposta. Esses quadros aparecerão no respectivo item descritivo de cada categoria mais adiante.

Para selecionar os livros que compõem o corpo de discussão deste artigo, os lugares das mulheres na literatura infanto-juvenil, analisando o papel da mulher de maneira não estereotipada, pautamos na experiência docente, tendo sido alguns dos títulos aqui trazidos já trabalhados em sala de aula. Após essa primeira ação, o passo seguinte foi definir as categorias que seriam utilizadas para trabalhar com as obras; em um terceiro momento iniciaram-se os trabalhos de detalhar as palavras-chave de cada livro e o momento da história que tematizava a mulher emancipada por sua identidade.

Utilizamos Paulo Freire como estrutura de análise conceitual e filosófica para dialogar com as obras escolhidas. O educador Paulo Freire acreditava em uma educação transformadora onde há o processo de ensino e aprendizagem e não apenas a transmissão de conteúdo. No contexto deste artigo, as mulheres seriam agentes sociais e não mais como coisas, objetos ou binarismos.

QUADRO 1 - QUADRO GERAL DOS LIVROS ANALISADOS

\begin{tabular}{|c|c|}
\hline Livros & Temas relevantes para o artigo \\
\hline A moça tecelã (Marina Colasanti) & $\begin{array}{c}\text { Busca por identidade, autonomia da mulher, } \\
\text { autoconfiança adquirida }\end{array}$ \\
\hline A bolsa amarela (Lygia Bojunga) & $\begin{array}{c}\text { Busca por identidade, questão de gênero, perspectiva } \\
\text { feminina sobre as imposições sociais }\end{array}$ \\
\hline Marcelo, marmelo, martelo ${ }^{3}$ (Ruth Rocha) & Busca por identidade, estereótipos de gênero \\
\hline $\begin{array}{l}\text { Malala, a menina que queria ir para a escola } \\
\text { (Adriana Carranca) }\end{array}$ & $\begin{array}{c}\text { Autonomia da mulher, empoderamento, luta política, } \\
\text { questão de gênero, cultura paquistanesa }\end{array}$ \\
\hline Chapeuzinho Amarelo (Chico Buarque) & Empoderamento, autoconfiança \\
\hline ...E o príncipe foi pro brejo! (Suppa) & Autonomia da mulher, empoderamento \\
\hline Até as princesas soltam pum (Ilan Brenman) & Quebra de estereótipos de gênero, relação pai-filha \\
\hline $\begin{array}{l}\text { O que os meninos fazem, o que as meninas fazem } \\
\text { (Ilan Brenman) }\end{array}$ & Quebra de estereótipos de gênero, empoderamento \\
\hline $\begin{array}{l}\text { Histórias à brasileira - A donzela guerreira e outras } \\
\text { (Ana Maria Machado) }\end{array}$ & Quebra de estereótipo de gênero, empoderamento \\
\hline $\begin{array}{l}\text { Extraordinárias: mulheres que revolucionaram o Brasil } \\
\text { (Duda Porto de Souza e Aryane Cararo) }\end{array}$ & $\begin{array}{c}\text { Empoderamento feminino, questões históricas sob } \\
\text { a perspectiva feminina, biografias de mulheres } \\
\text { historicamente importantes }\end{array}$ \\
\hline A princesa e a ervilha (Rachel Isadora) & $\begin{array}{l}\text { Empoderamento feminino, padrões socioculturais, } \\
\text { cultura africana }\end{array}$ \\
\hline $\begin{array}{l}\text { Grandes mulheres que mudaram o mundo (Kate } \\
\text { Pankhurst) }\end{array}$ & $\begin{array}{c}\text { Empoderamento feminino, biografias de importantes } \\
\text { personalidades históricas }\end{array}$ \\
\hline $\begin{array}{c}\text { Histórias de ninar para garotas rebeldes - Volumes I } \\
\text { e II } \\
\text { (Elena Favilli e Francesca Cavallo) }\end{array}$ & $\begin{array}{c}\text { Empoderamento feminino, questões históricas sob } \\
\text { a perspectiva feminina, biografias de mulheres } \\
\text { historicamente importantes }\end{array}$ \\
\hline Diferente como Chanel (Elizabeth Matthews) & $\begin{array}{c}\text { Empoderamento feminino, autonomia, autoconfiança, } \\
\text { quebra de padrões socioculturais }\end{array}$ \\
\hline $\begin{array}{c}\text { Curiosa, Tagarela e Vaidosa (Michel Piquemal } \\
\text { e Bruno Robert) }\end{array}$ & $\begin{array}{l}\text { Relação pai-filha, autonomia das mulheres, quebra de } \\
\text { padrões culturais }\end{array}$ \\
\hline $\begin{array}{l}\text { A revolta das princesas (Lisbeth Renardy e } \\
\text { Céline Lamour-Crochet) }\end{array}$ & $\begin{array}{c}\text { Busca por igualdade de direitos entre os gêneros, } \\
\text { sororidade }\end{array}$ \\
\hline As mulheres e os homens (Equipo Plantel) & $\begin{array}{c}\text { Quebra de padrões de gênero, debate histórico e } \\
\text { cultural }\end{array}$ \\
\hline
\end{tabular}

\footnotetext{
${ }^{3} \mathrm{O}$ referido livro é formado por três contos, incluindo o que dá nome ao livro, porém para a pesquisa proposta analisaremos apenas o terceiro conto da obra de nome Teresinha e Gabriela.
} 
CONCLUSÃO

\begin{tabular}{|c|c|}
\hline Livros & Temas relevantes para o artigo \\
\hline Píppi Meialonga (Astrid Lindgren) & $\begin{array}{c}\text { Autonomia da mulher, empoderamento, quebra de } \\
\text { padrões de gênero }\end{array}$ \\
\hline A princesa sabichona (Babette Cole) & Autonomia da mulher, escolha pelo seu destino \\
\hline $\begin{array}{c}\text { Aventuras de Alice no país das Maravilhas e Através } \\
\text { do espelho e o que Alice encontrou por lá } \\
\text { (Lewis Carroll) }\end{array}$ & $\begin{array}{c}\text { Busca por identidade, encorajamento pela autonomia } \\
\text { da mulher }\end{array}$ \\
\hline $\begin{array}{c}\text { As cientistas - 50 mulheres que mudaram o mundo } \\
\text { (Rachel Ignotofsky) }\end{array}$ & $\begin{array}{c}\text { Empoderamento feminino, relatos históricos pela } \\
\text { perspectiva feminina }\end{array}$ \\
\hline
\end{tabular}

FONTE: AUTORES

Nesses livros a história se desenrola de modo a evidenciar o protagonismo da personagem feminina, sua autonomia e habilidade de tomar decisões em sua vida. Aspectos esses que aparecem encobertos em tantos outros livros da literatura mundial difundida há anos e que consideramos serem essenciais para que jovens se espelhem e sintam-se engajadas a serem também autoras de suas próprias histórias de vida.

Os livros foram analisados a partir de uma visão geral de toda a história apresentada, personagens envolvidos, título, capa, entre outros pontos. Feito isso eles foram categorizados entre os aspectos pré-selecionados já citados anteriormente: empoderamento feminino; participação política; identidade e a mulher emancipada e os contos de fadas. As ferramentas utilizadas nesse processo de análise de conteúdo foram: Leitura do conto; segunda leitura analisando o sentido; terceira leitura colocando a obra nas categorias escolhidas; análise de conteúdo do conto; Debate sobre o conjunto dos contos escolhidos à luz das teorias relacionadas às categorias: empoderamento feminino, participação política, identidade, a mulher emancipada e os contos de fadas.

\section{DISCUSSÃO E ANÁLISE DAS CATEGORIAS}

Neste item discutiremos cada categoria de análise em particular, bem como cada título dos livros selecionados para compor este trabalho.

\section{EMPODERAMENTO FEMININO}

A primeira categoria escolhida para trabalharmos com os livros selecionados denomina-se Empoderamento Feminino, tendo como objetivo evidenciar situações literárias em que a personagem feminina teve acesso ao conhecimento, por meio dele "empoderou" a si mesma e por fim, uniu-o à uma ação transformadora, passando assim de sujeitada a sujeito ativo e potencialmente modificadora de uma realidade que a limitava.

Ao usar a terminologia empoderamento nesse trabalho, estamos visando o uso do termo como um instrumento de emancipação política e social. Alguns críticos preferem usar fortalecimento, pois julgam que a palavra advinda do inglês empowerment estaria confinada à subjugação implícita nas relações de poder (BERTH, 2019, p. 23), no entanto, a intenção da linha de pesquisa aqui apresentada é relacioná-la com "uma postura de enfrentamento da opressão para eliminação da situação injusta e equalização de existência em sociedade" (BERTH, 2019, p. 23). Defendemos aqui, portanto, a utilização do termo empoderamento quando pensado como "um instrumento de emancipação política e social” (BERTH, 2019, P. 22) e que utiliza para isso a informação como ferramenta de libertação. Ainda nas palavras de Berth:

[...] os processos de empoderamento, embora possam receber estímulos externos diversos da academia, das artes, da política, da psicologia, das vivências cotidianas etc., são uma movimentação interna de tomada de consciência ou do despertar de diversas potencialidades que definirão estratégias de enfrentamento das práticas do sistema de dominação machista e racista (2019, p. 25). 
Desse modo, o empoderamento ocorre quando além de perceber as instâncias que o oprime, o indivíduo também atua no sentido de mudar de alguma forma as relações de poder existentes.

\section{QUADRO 2 - CATEGORIA EMPODERAMENTO FEMININO}

\begin{tabular}{|c|c|}
\hline Título do livro & Parte destacada \\
\hline $\begin{array}{l}\text { A moça tecelã (Marina } \\
\text { Colasanti) }\end{array}$ & $\begin{array}{l}\text { Momento em que a Moça Tecelã não se vê feliz com a escolha que fez e } \\
\text { decide que tem o poder de fazer novas escolhas “A noite acabava quando o } \\
\text { marido estranhando a cama dura, acordou, e, espantado, olhou em volta. Não } \\
\text { teve tempo de se levantar. Ela já desfazia o desenho escuro dos sapatos, e ele } \\
\text { viu seus pés desaparecendo, sumindo as pernas. Rápido, o nada subiu-lhe pelo } \\
\text { corpo, tomou o peito aprumado, o emplumado chapéu”. (p. 12) }\end{array}$ \\
\hline $\begin{array}{l}\text { A bolsa amarela (Lygia } \\
\text { Bojunga) }\end{array}$ & $\begin{array}{c}\text { “Comecei a pensar diferente. Raquel decide que não tem que esconder sua } \\
\text { vontade de escrever por causa dos outros”. (p. 103) } \\
\text { “Pela primeira vez na vida a personagem acha seu nome Raquel um nome } \\
\text { legal e resolve se desfazer dos nomes masculinos que ela guardava em } \\
\text { segredo”. (p. 131) }\end{array}$ \\
\hline $\begin{array}{l}\text { Malala, a menina que queria ir } \\
\text { para a escola } \\
\text { (Adriana Carranca) }\end{array}$ & $\begin{array}{l}\text { Malala foi educada pelos pais a acreditar em sua voz e em seu poder de ação. } \\
\text { Tornou-se porta voz dentre outros pontos o direito à educação e de igualdade } \\
\text { de direitos. Enfrentou um sistema totalitário sofreu um atentado e é porta voz } \\
\text { dos direitos das mulheres. }\end{array}$ \\
\hline $\begin{array}{l}\text { Chapeuzinho Amarelo (Chico } \\
\text { Buarque) }\end{array}$ & $\begin{array}{l}\text { Chapeuzinho Amarelo perde o medo do lobo mau e com isso aprende a lidar } \\
\text { com vários outros medos que tinha. (p. 30) }\end{array}$ \\
\hline $\begin{array}{l}\text {...E o príncipe foi pro brejo! } \\
\text { (Suppa) }\end{array}$ & $\begin{array}{l}\text { A princesa reconhece que não está em um relacionamento feliz após casar-se } \\
\text { com o príncipe e este acaba tornando-se um sapo aos seus olhos. Ela então } \\
\text { termina o casamento e ambos ficam felizes com o seu destino. }\end{array}$ \\
\hline $\begin{array}{l}\text { O que os meninos fazem, o } \\
\text { que as meninas fazem (Ilan } \\
\text { Brenman) }\end{array}$ & $\begin{array}{l}\text { Embora inicialmente o livro relate brincadeiras separadas de meninos e } \\
\text { de meninas, as meninas começam a questionar o papel a elas destinado e } \\
\text { confrontam os estereótipos de gênero brincando de “coisas de menino” e } \\
\text { incitando os meninos a fazerem o mesmo. Este é o toque genial do livro pois } \\
\text { ele mistura as brincadeiras, mostrando que a criança tem o poder de escolha } \\
\text { independentemente do gênero. Por meio de }\end{array}$ \\
\hline $\begin{array}{l}\text { Histórias à brasileira - A } \\
\text { donzela guerreira e outras (Ana } \\
\text { Maria Machado) }\end{array}$ & $\begin{array}{l}\text { O conto selecionado mostra a personagem feminina que se propõe a ir para a } \\
\text { guerra fingindo ser um homem para defender sua família. Mesmo com medo e } \\
\text { contra a vontade de seus pais, ela decide seu destino. }\end{array}$ \\
\hline $\begin{array}{l}\text { Diferente como Chanel } \\
\text { (Elizabeth Matthews) }\end{array}$ & $\begin{array}{l}\text { O livro biográfico traz a história de Coco Chanel, uma das mais famosas } \\
\text { estilistas de todos os tempos, mostrando que ela teve uma infância dura de } \\
\text { pobreza e muitas incertezas, na qual ela, acreditando em sua personalidade } \\
\text { forte, teve a ousadia de ser diferente do que todos esperavam. }\end{array}$ \\
\hline $\begin{array}{l}\text { Píppi Meialonga (Astrid } \\
\text { Lindgren) }\end{array}$ & $\begin{array}{l}\text { Uma menina órfã vive sozinha e acompanhada de seus amigos passa por } \\
\text { muitas aventuras divertidas. Píppi é inteligente, ousada e corajosa. }\end{array}$ \\
\hline $\begin{array}{l}\text { A princesa sabichona (Babette } \\
\text { Cole) }\end{array}$ & $\begin{array}{l}\text { A princesa tem o poder de escolha sobre sua vida e em relação a casar-se ou } \\
\text { não com um príncipe. }\end{array}$ \\
\hline $\begin{array}{c}\text { Aventuras de Alice no país } \\
\text { das Maravilhas e Através do } \\
\text { espelho e o que Alice encontrou } \\
\text { por lá (Lewis Carroll) }\end{array}$ & $\begin{array}{l}\text { Alice é uma garota curiosa que segue as suas vontades e vivencia inúmeras } \\
\text { aventuras em um mundo lúdico. Inusitados personagens que aparecem ao } \\
\text { longo da história, propõem diálogos profundos e de fundo filosófico. }\end{array}$ \\
\hline $\begin{array}{c}\text { Extraordinárias: mulheres } \\
\text { que revolucionaram o Brasil } \\
\text { (Duda Porto de Souza e Aryane } \\
\text { Cararo) }\end{array}$ & $\begin{array}{c}\text { O livro traz biografias de mulheres brasileiras e abrasileiradas que de algum } \\
\text { modo marcaram o tempo em que viveram e são ícones femininas da nossa } \\
\text { história. }\end{array}$ \\
\hline
\end{tabular}

FONTE: AUTORES 


\section{PARTICIPAÇ̃̃O POLÍTICA}

Podemos falar de três momentos históricos após o século XVIII quando o assunto é a igualdade de direitos entre mulheres e homens. De acordo com a psicanalista e professora Maria Homem no livro Coisa de menina? Uma conversa sobre gênero, sexualidade, maternidade e feminismo (2019) no qual ela dialoga com o também psicanalista e professor Contardo Calligaris, o primeiro momento é a da mulher vista como reprodutora e um bem intercambiável. No segundo momento a mulher passa a ter alguma autoridade, mas a saída ocidental para o dilema da luta pela emancipação feminina foi fazer uma suposta divisão na qual a mulher pretensamente teria "o poder doméstico", o espaço privado e a gestão do lar, e o homem ficaria com a gestão do espaço público, da vida política, cultural e das narrativas simbólicas dominantes. (2019, p. 23). É nesse período também que se enaltece a figura da mulher como mãe. Porém "a narrativa de igualdade diferenciada do século XIX foi uma estratégia que se revelou enganadora, pois na prática os gêneros permaneceram em grande medida desiguais. E o lugar concedido à mulher como rainha do lar estava longe de ser suficiente" (2019, p. 23). Chegamos então ao terceiro momento, no século XX, com a ideia revolucionária de direitos civis, humanos e de igualdade efetiva entre os indivíduos, que culmina nas décadas de 1960 e 1970 com "a mulher cada vez mais recusando esse domínio do poder feminino no lar, no espaço privado” (2019, p. 24).

Daí a importância de criarmos um tópico nesse artigo que abranja a figura da mulher como personagem dos livros infanto-juvenis que demande participação política em cenários para além da vida doméstica. "A mulher tem, no mínimo, uma tripla jornada hoje. Ela tem múltiplas funções: é mãe na casa, cidadã na polis e trabalhadora no mercado. E existe ainda uma outra grande função que é exercida - ou demanda a ser exercida -, que é a de ser uma mulher desejada” (HOMEM, 2019, p. 80).

Abordar livros que nos mostrem pessoas reais ou personagens idealizadas que demonstram atitudes que promovam uma ruptura com o pensamento de dominação masculina é essencial para exemplificar que essa é uma luta simbólica que se promove há gerações e na qual estamos avançando, e também incentivar que meninas enxerguem as situações sexistas que ainda enfrentam e se posicionem contra, e que meninos compreendam quais são as demandas do feminismo juntamente com a importância do movimento ser voltado para todos os cidadãos, independentemente do gênero (ADICHIE 2018, p. 38).

QUADRO 3 - CATEGORIA PARTICIPAÇÃO POLIITICA

\begin{tabular}{|c|c|}
\hline Título do livro & Parte destacada \\
\hline $\begin{array}{l}\text { Malala, a menina que } \\
\text { queria ir para a escola } \\
\text { (Adriana Carranca) }\end{array}$ & $\begin{array}{l}\text { Reconta de maneira lúdica a história real da menina paquistanesa que desde } \\
\text { a infância conviveu com os livros e com a guerra, e na adolescência teve o } \\
\text { posicionamento de querer ir para a escola quando todas as meninas foram proibidas } \\
\text { de estudar em seu país. Com isso, sofreu o atentado no qual foi baleada, sobreviveu } \\
\text { e levou ao mundo a sua luta pela Educação. }\end{array}$ \\
\hline $\begin{array}{l}\text { Histórias de ninar para } \\
\text { garotas rebeldes } \\
\text { (Elena Favilli e Francesca } \\
\text { Cavallo) }\end{array}$ & $\begin{array}{l}\text { Relata biograficamente sobre mulheres políticas, tais quais: Ameenah Gurib-Fakim } \\
\text { (presidenta e cientista - p. 10), Balkissa Chabou (ativista - p. 28), Elizabeth I } \\
\text { (rainha - p. 46), Evita Perón (política - p. 50), Helen Keller (ativista - p. 66), } \\
\text { Hillary Clinton (política - p. 68), Michelle Obama (advogada e ex-primeira dama - } \\
\text { p. 144) entre outras. }\end{array}$ \\
\hline $\begin{array}{l}\text { Diferente como Chanel } \\
\text { (Elizabeth Matthews) }\end{array}$ & $\begin{array}{l}\text { O livro mostra como Coco Chanel mudou a rotina das mulheres trabalhadoras ao } \\
\text { criar roupas mais confortáveis para além do uso do espartilho da época; causando } \\
\text { assim uma revolução na participação feminina nas fábricas e demais setores } \\
\text { sociais. }\end{array}$ \\
\hline $\begin{array}{l}\text { Curiosa, Tagarela e } \\
\text { Vaidosa (Michel Piquemal } \\
\text { e Bruno Robert) }\end{array}$ & $\begin{array}{l}\text { A história mostra as três personagens, filhas do rei, vivenciando a vida política do } \\
\text { castelo e após o ocorrido, o pai as nomeia ministras. }\end{array}$ \\
\hline
\end{tabular}




\begin{tabular}{|c|c|}
\hline Título do livro & Parte destacada \\
\hline $\begin{array}{l}\text { As cientistas - } 50 \\
\text { mulheres que mudaram } \\
\text { o mundo (Rachel } \\
\text { Ignotofsky) }\end{array}$ & $\begin{array}{l}\text { Há uma linha do tempo ressaltando feitos importantes e a participação das } \\
\text { mulheres em situações políticas (p. } 32 \text { e 33). } \\
\text { O livro fala de uma maneira mais específica de algumas mulheres que } \\
\text { desempenharam um importante papel na vida política, tais como: Rita Levi- } \\
\text { Montalcini (neurologista e senadora italiana - p.63) e Mamie Phipps Clark } \\
\text { (Psicóloga e ativista de direitos civis - p. 71). } \\
\text { O livro traz também estatísticas sobre o aumento da participação das mulheres na } \\
\text { força de trabalho e nos estudos nos campos de ciência, tecnologia, engenharia e } \\
\text { matemática (p. } 84 \text { e 85). }\end{array}$ \\
\hline $\begin{array}{l}\text { Grandes mulheres que } \\
\text { mudaram o mundo (Kate } \\
\text { Pankhurst) }\end{array}$ & $\begin{array}{c}\text { Com histórias de mulheres que se tornaram simbólicas por seus feitos } \\
\text { historicamente, o livro traz a sua biografia e apresenta diversas informações sobre } \\
\text { a profissão que elas escolheram, de modo a incentivar meninas a viverem seus } \\
\text { sonhos. }\end{array}$ \\
\hline $\begin{array}{l}\text { As cientistas - } 50 \\
\text { mulheres que mudaram } \\
\text { o mundo (Rachel } \\
\text { Ignotofsky) }\end{array}$ & $\begin{array}{l}\text { Há uma linha do tempo ressaltando feitos importantes e a participação das } \\
\text { mulheres em situações políticas (p. } 32 \text { e 33). } \\
\text { O livro fala de uma maneira mais específica de algumas mulheres que } \\
\text { desempenharam um importante papel na vida política, tais como: Rita Levi- } \\
\text { Montalcini (neurologista e senadora italiana - p.63) e Mamie Phipps Clark } \\
\text { (Psicóloga e ativista de direitos civis - p. 71). } \\
\text { O livro traz também estatísticas sobre o aumento da participação das mulheres na } \\
\text { força de trabalho e nos estudos nos campos de ciência, tecnologia, engenharia e } \\
\text { matemática (p. } 84 \text { e 85). }\end{array}$ \\
\hline
\end{tabular}

FONTE: AUTORES

\section{IDENTIDADE}

A identidade é discutida aqui por meio do processo de rompimento da categoria sexo como definidor das identidades sociais. Depois veio o feminismo do século XX para inquietar a ordem e promover a diferenciação dos termos sexo e gênero, no qual o primeiro passaria a se referir à denominação biológica de homem e mulher, e o segundo faria jus à uma construção cultural sobre o que é ser homem e o que é ser mulher. Definição essa que ainda não ficou clara para quem está do lado de fora de movimentos sociais que se comunicam com o feminismo, e continuam defendendo que as identidades estão postas e definidas por um viés conservador (RIBEIRO, 2019).

No entanto, dentro dos debates teóricos feministas essa visão de sexo e gênero não só já foi amplamente discutida, como já está sendo ultrapassada por um outro olhar possível e potencialmente mais revolucionário. É o que nos mostra a filósofa pós-estruturalista estadunidense Judith Butler em uma de suas obras mais famosas originalmente publicada em 1990 nos Estados Unidos: Problemas de gênero: feminismo e subversão da identidade (2019), na qual ela nos mostra que não é possível que haja a libertação da mulher sem que antes se subverta a identidade de mulher. A autora se opõe teoricamente ao estruturalismo que dita a oposição binária entre sexo e gênero, defendendo que os dois termos são categorias sociais e culturalmente construídos. Ao interrogar pressupostos que já estariam de um certo modo acomodados dentro do debate teórico feminista, tem-se o propósito de ampliar nossas percepções quanto ao que é ser homem e o que é ser mulher na sociedade atual; e a partir do engrandecimento das discussões à cerca de identidade, contemplar com isso a multiplicidade de sexualidades possíveis - que estão tão visíveis na contemporaneidade, mas ao mesmo tempo sendo escondidas por aqueles que preferem não romper com o pseudo-equilíbrio estabelecido pela hegemonia cisheteronormativa.

Como evidenciado no título do livro de Butler (2019), as questões de gênero perpassam o feminismo e a subversão da identidade, já que para a autora não é possível que falemos em apenas uma identidade, no singular, mas sim que enxerguemos múltiplas identidades, no plural. Para alcançar esse 
questionamento, Butler parte do princípio de teorizar o próprio conceito de identidade como uma característica descendente da experiência de cada indivíduo e não como um ideal normativo - algo pronto e acabado. Ela também nos propõe a pensar:

[...] como as práticas reguladoras que governam o gênero também governam as noções culturalmente inteligíveis de identidade? Em outras palavras, a 'coerência' e a 'continuidade’ da 'pessoa’4 não são características lógicas ou analíticas da condição de pessoa, mas, ao contrário, normas de inteligibilidade socialmente instituídas e mantidas. Em sendo a 'identidade' assegurada por conceitos estabilizadores de sexo, gênero e sexualidade, a própria noção de 'pessoa' se veria questionada pela emergência cultural daqueles seres cujo gênero é 'incoerente' ou 'descontínuo', os quais parecem ser pessoas, mas não se conformam às normas de gênero da inteligibilidade cultural pelas quais as pessoas são definidas (BUTLER, 2019, p. 43).

Quando Márcia Tiburi afirma que "O sexo faz parte de um sistema de crenças. Ele é um signo de controle das pessoas, e o controle é algo que as religiões e os Estados sabem - e sempre souberam - fazer muito bem” (2018, p. 90) essa é uma colocação que já nos propõe rever todas as definições que um dia nos foram apresentadas em termos identitários. A teoria descrita por Butler se faz ainda mais transformadora ao sugerir que gênero, ao ser visto como algo construído culturalmente pelo grupo social ao qual pertence, também pode ser colocado como um produto da cultura, no sentido de que este estaria determinado e fixado tanto quanto o sexo é estabelecido pela biologia.

Não chegaremos a um denominador comum no debate sexo $x$ gênero $x$ identidade e esse nem é nosso objetivo. Afinal, como já dizia o poeta espanhol Antônio Machado "o caminho se faz ao caminhar". É preciso ter em vista que o processo de debater ideias e vertentes já é em si um dos resultados daquilo que estamos propondo a nós mesmos: rever os conceitos que nos foram colocados em dado momento como algo definido. Ou ainda nas palavras de Paulo Freire: "Ninguém caminha sem aprender a caminhar, sem aprender a fazer o caminho caminhando, refazendo o sonho pelo qual se pôs a caminhar" (1997, p. 155). Nos livros selecionados para compor essa categoria de análise, evidenciamos personagens femininas que por sua atitude projeta-se uma identidade de autoconhecimento, centrada no Ser, que busca sua potencialidade de ser sujeito de sua história.

QUADRO 4 - CATEGORIA IDENTIDADE

\begin{tabular}{|c|c|c|}
\hline Título do livro & Parte destacada \\
\hline $\begin{array}{c}\text { A moça tecelã (Marina } \\
\text { Colasanti) }\end{array}$ & A moça tecelã sente-se sozinha e pensa como seria bom ter um marido ao lado (p. 5). \\
\hline $\begin{array}{c}\text { A bolsa amarela (Lygia } \\
\text { Bojunga) }\end{array}$ & $\begin{array}{c}\text { A menina Raquel evidencia que tem três desejos que crescem dentro dela e ela quer } \\
\text { esconder: a vontade de crescer logo, a vontade de ter nascido menino ao invés de } \\
\text { menina e a vontade de escrever (p. 9). }\end{array}$ \\
\hline $\begin{array}{c}\text { Marcelo, marmelo, } \\
\text { martelo (Ruh Rocha) }\end{array}$ & $\begin{array}{c}\text { No conto Teresinha e Gabriela as personagens entram em conflito com a própria } \\
\text { identidade ao quererem ser uma igual à outra. O conflito é resolvido de forma } \\
\text { saudável ao combinarem características escolhidas por elas e ambas virarem } \\
\text { amigas (p. 25). }\end{array}$ \\
\hline $\begin{array}{c}\text { Diferente como Chanel } \\
\text { (Elizabeth Matthews) }\end{array}$ & $\begin{array}{c}\text { Coco Chanel é mostrada como uma pessoa de muita identidade desde criança } \\
\text { quando era excluída pela sua condição social e lutou para mostrar ao mundo a sua } \\
\text { força e determinação em realizar seu sonho. }\end{array}$ \\
\hline $\begin{array}{c}\text { Curiosa, Tagarela e } \\
\text { Vaidosa (Michel Piquemal } \\
\text { e Bruno Robert) }\end{array}$ & $\begin{array}{c}\text { Cada uma das três personagens exibe personalidade diferente e estão dispostas a } \\
\text { enfrentar a resistência do pai em aceitá-las. Até o fim da história, todas mantêm-se } \\
\text { firmes em suas personalidades, fazendo com que inclusive o rei as respeitem. }\end{array}$ \\
\hline
\end{tabular}

${ }^{4}$ Grifos da autora. 


\begin{tabular}{|c|c|}
\hline Título do livro & Parte destacada \\
\hline $\begin{array}{l}\text { As mulheres e os homens } \\
\text { (Equipo Plantel) }\end{array}$ & $\begin{array}{c}\text { O livro relata a todo momento que o comportamento que temos diante da sociedade } \\
\text { nos foi ensinado culturalmente e que nada têm a ver com o fato de sermos } \\
\text { homens ou sermos mulheres; ele evidencia que as atitudes que se esperam de } \\
\text { um determinado gênero foram aprendidas e determinadas pelo convívio social e } \\
\text { demonstra a importância de conseguirmos enxergar para além dos estereótipos de } \\
\text { gênero. }\end{array}$ \\
\hline \multirow{3}{*}{$\begin{array}{l}\text { Aventuras de Alice no país } \\
\text { das Maravilhas e Através } \\
\text { do espelho e o que Alice } \\
\text { encontrou por lá } \\
\text { (Lewis Carroll) }\end{array}$} & $\begin{array}{l}\text { Toda a viagem de Alice no decorrer do livro trata-se de uma busca pela sua própria } \\
\text { identidade; ao encontrar a lagarta, por exemplo, ela é questionada sobre quem ela é } \\
\text { e passa a fazer esse questionamento a si mesma por não ter uma resposta exata (p. } \\
55 \text { ) }\end{array}$ \\
\hline & $\begin{array}{l}\text { No diálogo com a Rainha, a mesma, alerta Alice diversas vezes sobre a importância } \\
\text { de pensar em quem você é e valorizar toda sua evolução naquela jornada (p. 227) }\end{array}$ \\
\hline & $\begin{array}{l}\text { Há o momento clássico em que a Alice encontra com o Gato durante sua } \\
\text { caminhada e se vê perdida, ao perguntar qual caminho deve seguir, o gato a } \\
\text { questiona sobre onde ela quer chegar, ao responder que não sabe para onde quer ir, } \\
\text { o gato sabiamente a alerta: "Então não importa que caminho tome” (p. 77). }\end{array}$ \\
\hline
\end{tabular}

FONTE: AUTORES

\section{A MULHER EMANCIPADA E OS CONTOS DE FADAS}

Segundo Bruno Betelheim no “A psicanálise dos contos de fadas” (1980) há indícios que os primeiros contos de fadas sejam de origem céltica e datem do início do século II a.C. E é justamente por sobreviverem por tantos anos e ainda encantarem muitas crianças, que essa categoria merece atenção especial no que diz respeito à educação infantil. Inicialmente, como contos transmitidos pela tradição oral, os contos de fadas não eram dirigidos ao público infantil.

O francês Charles Perrault (1628 - 1703) foi um dos pioneiros no gênero, adaptando contos e lendas da Idade Média, dando-lhes fortes doses de terror, sadismo e tirania. São obras famosas de Perrault: Cinderela, A Bela adormecida, O pequeno polegar, O Gato de Botas, Chapeuzinho Vermelho, entre outros. Apenas no século XIX, outra coleta de contos populares foi realizada, dessa vez na Alemanha, pelos irmãos Jacob (1785 - 1863) e Wilhelm (1786 - 1859) Grimm, cujas principais obras foram: Branca de Neve, João e Maria e Rapunzel. Sob influência do Romantismo da época, os irmãos Grimm apresentaram uma nova versão de Cinderela e Chapeuzinho Vermelho, onde foram retirados trechos que julgavam não recomendáveis devido à sua violência. Originalmente nos contos de Charles Perrault em Cinderela, por exemplo, as irmãs a mando da madrasta cortam os dedos do próprio pé e o calcanhar numa tentativa de diminuir seu tamanho para calçar o sapatinho de cristal da protagonista e casar-se com o príncipe; e em Chapeuzinho Vermelho o lobo sai como vencedor ao devorar a avó e posteriormente a protagonista em uma cena nada convencional na qual ele, na cama da avó, convida Chapeuzinho a despir-se e deitar-se com ele, e ao fazê-lo é devorada pelo lobo. Apenas na versão dos irmãos Grimm é que há a figura do caçador que salva a menina das garras do lobo e aplica-lhe uma vingança colocando pedras em sua barriga, fazendo assim com que o bem vença o mal.

Já o dinamarquês Hans Christian Andersen (1805 - 1875) preferiu criar suas próprias histórias, projetando nelas seus ideais românticos e de generosidade humana. Suas obras são: A pequena sereia, As roupas novas do rei, $O$ patinho feio e $O$ soldadinho de chumbo entre outras.

Além desses, são também importantes para a literatura infantil nomes como Lewis Carroll, autor inglês que escreveu Alice no país das maravilhas; Carlo Collodi, escritor italiano responsável pela obra Pinóquio; e o escocês James Barrie, criador de Peter Pan.

Sob a ótica da Psicanálise, Bruno Bettelheim, renomado psicólogo infantil, afirma em seu livro $A$ psicanálise dos contos de fadas (1980), que os contos desenvolvem a capacidade de fantasia infantil na medida em que oferecem novas dimensões à imaginação da criança que ela não descobriria por si só; eles 
fornecem os escapes necessários que se comunicam com os medos internos próprios da primeira infância e com suas ansiedades, aliviando assim as pressões exercidas por essas questões.

Por trazerem quase em sua totalidade a personagem principal na figura feminina, os contos de fadas tornam-se um ponto importante, porém trazendo à tona livros atuais em que se referencie o gênero literário com uma abordagem feminista. Por que queremos destacar obras que mostrem uma mudança na postura da personagem feminina que possivelmente afeta toda a narrativa em si? Responderemos com uma advertência feita por Pierre Bourdieu em A dominação masculina (2019) de que devemos "Lembrar que aquilo que, na história, aparece como eterno não é mais do que o produto de um trabalho de eternização que compete a instituições interligadas, tais como a Família, a Igreja, a Escola” (2019, p. 8); e nas palavras de Márcia Tiburi (2018) "Não podemos esquecer que estamos em um tempo histórico e nossas ações pertencem a esse tempo” (2018, p. 89). A princípio as citações parecem nos trazer algo de fácil entendimento, mas se levarmos em consideração o quanto ainda reproduzimos padrões de gênero e de estereótipos que se sustentam há gerações, veremos que ainda há muito o que se esclarecer em relação ao tema para que futuramente as pessoas se vejam mais livres de julgamentos de fundo estético e moral do comportamento humano. E que nós, no papel de educadoras e educadores, proporcionemos ações que acelerem esse processo de emancipação cultural. Para fins desta categoria selecionamos livros que transformam as histórias dos contos de fada, onde a mulher casa com um príncipe e vive feliz para sempre, ou é salva por um homem, ou o estereótipo da princesa que carrega como sinônimo a mulher perfeita.

QUADRO 5 - CATEGORIA A MULHER EMANCIPADA E OS CONTOS DE FADAS

\begin{tabular}{|c|c|}
\hline Título do livro & Parte destacada \\
\hline $\begin{array}{l}\text { Chapeuzinho Amarelo } \\
\text { (Chico Buarque) }\end{array}$ & $\begin{array}{l}\text { Título do livro que faz referência ao clássico conto de Chapeuzinho Vermelho, em } \\
\text { que a menina é indefesa e tola, diferente da personagem Chapeuzinho Amarelo que } \\
\text { percebe seus medos e os ressignifica, a passagem da ilustração de Ziraldo Lobo/Bolo } \\
\text { é um momento importante desta transformação. }\end{array}$ \\
\hline $\begin{array}{l}\text {...E o príncipe foi pro } \\
\text { brejo! (Suppa) }\end{array}$ & $\begin{array}{l}\text { Faz alusão aos contos de fadas ao começar a partir do "Se casaram e não foram } \\
\text { felizes para sempre” (p. 4). O fim descontrói a base dos contos de fadas modernos, e } \\
\text { que a história de uma princesa deve terminar com um príncipe. }\end{array}$ \\
\hline $\begin{array}{l}\text { Até as princesas soltam } \\
\text { pum (Ilan Brenman) }\end{array}$ & $\begin{array}{l}\text { Reconta a história das princesas clássicas a partir de um olhar cômico e que acaba } \\
\text { com o estereótipo de princesa perfeita. }\end{array}$ \\
\hline $\begin{array}{l}\text { A princesa e a ervilha } \\
\text { (Rachel Isadora) }\end{array}$ & $\begin{array}{c}\text { Reconto do clássico de mesmo nome, porém com a mudança de trazer somente } \\
\text { personagens negros e apresentar a cultura africana. }\end{array}$ \\
\hline $\begin{array}{l}\text { A revolta das princesas } \\
\text { (Lisbeth Renardy e } \\
\text { Céline Lamour-Crochet) }\end{array}$ & $\begin{array}{l}\text { Apresenta várias das princesas de contos clássicos (Branca de Neve, Chapeuzinho } \\
\text { Vermelho, Cinderela, entre outras) reunidas pela causa de não querer mais aturar } \\
\text { tantos problemas para enfim alcançarem a felicidade. }\end{array}$ \\
\hline
\end{tabular}

FONTE: AUTORES

\section{CONSIDERAÇÕES FINAIS}

Este texto objetivou debater as potencialidades de livros infanto-juvenis que tratam o papel social da mulher de maneira a não reforçar os estereótipos. Este estudo buscou tratar de vários contos com importantes temas, portanto, o que se traduziu em abrangência perdeu-se em profundidade, reconhecemos também a sutileza das categorias e a falta de uma definição objetiva no sentido puro do termo, a escolha foi por abranger o maior número de obras ficando os aspectos metodológicos sem uma ancoragem nas categorias.

Por outro lado, este é um assunto que merece atenção dos pesquisadores e pesquisadoras que debatem os papéis sociais das mulheres e suas lutas por igualdade de direitos. Acreditamos que este artigo pode contribuir assim como os livros "Coisa de menina? Uma conversa sobre gênero, sexualidade, maternidade e feminismo" e "A mulher na literatura infanto-juvenil: revisão e perspectivas”. Os assuntos aqui 
levantados são de ordem socioconstrutivista e, portanto, caminham juntamente com as questões teóricas propostas por estudiosos da área e levantadas pela demanda social à medida que vamos evoluindo ao problematizar assuntos que antes eram normalizados.

Berth (2019) ao abordar o conceito de empatia, explica que esse não é um sentimento que podemos demonstrar em um dia e no outro não, pois trata-se de um sentimento que depende de toda "uma construção intelectual que demanda esforço, disponibilidade para aprender e ouvir. Tão mais empática a pessoa será quanto mais ela conhecer a realidade que denuncia uma opressão” (BERTH, 2019, p. 40). Lembrando sempre de um dos mais evidentes autores brasileiros a trabalhar os vínculos de exploração nas demandas sociais: "Freire apresenta uma densa análise sobre a sociedade de classes e sua relação de exploração com as classes menos favorecidas, entre as quais ele nomeia uma relação entre colonizador e colonizado, mostrando as implicações dessas relações desiguais” (BERTH, 2019, p. 41).

Trabalhamos alicerçados em Paulo Freire porque as obras do autor inegavelmente servem a um propósito de busca por caminhos e estratégias para a erradicação das desigualdades sociais. Objetivo este que pode ser encarado ainda como um sonho (distante?) nos tempos atuais em que em nosso país nos deparamos diariamente com debates alimentados pelo que Kristie Dotson denomina de pernicious ignorance - traduzido e explicado por Berth (2019) como ignorância perniciosa, ou seja, aquela que se beneficia da não instrumentalização da sociedade no sentido de viabilizar práticas que visem erradicar os problemas que geram tamanha desigualdade social como a que temos hoje. Ou seja, aqueles que estão - ou pensam estar - em uma posição privilegiada na escala social não tem interesse algum em conhecer sobre a realidade alheia (ou ainda realidade da qual o próprio indivíduo faz parte, mas nega pertencer), pois essa busca pela informação acabaria com uma ideia de status à qual ele briga para se manter confortavelmente.

Intrinsicamente a este movimento de anulação dos fatos sociais, está a violência epistemológica, que nas palavras de Márcia Tiburi em Feminismo em comum (2018) nos deixa “[...] diante de pessoas que usam termos sérios e que devem sempre levar ao avanço da pesquisa e do debate, de um modo populista e com fins de manutenção do poder” (2018, p. 74). É o que vimos ocorrer, por exemplo, com a terminologia identidade de gênero, que foi depreciada pela má-fé de conservadores misóginos que chegaram inclusive a afirmar a existência de objetos fálicos em creches e nomear de kit gay (nome claramente pejorativo) um folder feito na tentativa de explicar sobre respeito à diversidade sexual direcionado aos adolescentes e educadores do Ensino Médio - material este que foi elaborado por especialistas no programa de governo denominado Brasil sem homofobia. Com discursos que vão ao encontro do que as mentes mais reacionárias querem ouvir, essas teorias populares ganham grande projeção e acabam por se tornar uma verdade para aqueles que, pelos mais diferentes motivos, não farão uso de um pensamento mais reflexivo e crítico.

Este artigo problematizou o discurso presente em livros infanto-juvenis a partir do olhar proposto, buscamos um olhar crítico sobre a representação das mulheres na literatura, bem como os demais âmbitos sociais. A literatura apresentada permite ser um estímulo aos educadores e educandos na discussão sobre os papeis sociais e sua discussão e posterior transformação. Promovemos o debate sobre as relações construídas discursivamente, buscando desnaturalizar e desconstruir conceitos.

Nosso objetivo é apresentar estes livros para o debate escolar, localizando-os como possíveis incitadores aos estudantes a enxergarem os personagens e o enredo trazido pela história por outro panorama, reforçando o papel do educador e da educadora como reguladores das mensagens no ambiente escolar. Identificamos potencial emancipatório neste fazer docente, alertando como as histórias já na tenra infância pode trazer potenciais transformadores ou reprodutores.

As categorias de análise após a análise de conteúdo foram: Empoderamento Feminino, Participação Política, Identidade, A Mulher Emancipada e os Contos de Fadas. Para fins didáticos elaboramos quadros com os títulos e as palavras-chave e uma breve descrição que o enquadra na análise proposta.

Destacamos os contos em que: a personagem feminina (a) teve uma transformação de objeto para sujeito da história; (b) participa ativamente da política como produtora de conteúdo e agente histórica e social; (c) não naturaliza seu eu a uma identidade pré-definida; (d) que não é perfeita, e não espera o alguém, mas sim toma atitudes progressistas.

Por isso mesmo, defendemos que desde a educação infantil devemos trabalhar com as crianças de modo a estimulá-las a questionar toda e qualquer ideia de maneira saudável e visando formar jovens 
e adultos com autonomia no pensar e no agir. Os livros que foram positivamente analisados têm como objetivo mais do que propiciar um momento de leitura deleite em sala de aula, eles também buscam fornecer informações que - por muitas vezes fugirem da realidade de que chamamos de senso comum - não chegariam pelo meio de convivência comum da criança, e ainda oferecer a ela a possibilidade de reconhecimento (de si ou de outras) nas personagens encontradas nas histórias.

Não foi objeto deste estudo, porém devemos destacar que na literatura infantil outros formatos de corpo e orientação sexual ainda são poucos contemplados, podemos citar como exceção o livro infantil “Sex is a funny word” de Cory Silverberg publicado em 2015.

Estamos em um processo longo de busca por garantias de equidade de gênero, todavia, mais distantes de igualdade de gênero não-binário. Estudos de Reis e Pinho (2016), apenas para citar um exemplo, discute processos educativos sobre a construção não-binária de gêneros. Segundo Reis e Pinho: “a problematização das diferenças entre características naturais supostamente pré-discursivas e processo socioculturais para a compreensão de uma estruturação binária na concepção de gênero faz-se necessário" (REIS; PINHO, 2016, p.7). O espaço escolar deveria abarcar saberes sobre corpos, identidades e socializações.

Como educadores acreditamos que nossa luta se faz com livros. A partir deles é que podemos reinterpretar nosso mundo e ampliar nossas percepções. Michele Petit afirma que "o escritor quebra os estereótipos, renova a linguagem, caça os clichês - o bom escritor, ao menos. E é um dos raros que fala das contradições e das ambivalências das quais somos feitos” (2008, p. 41).

\section{REFERÊNCIAS}

ADICHIE, C. N. Sejamos todos feministas. São Paulo: Reviravolta. 2018.

BARDIN, L. Análise de Conteúdo. Lisboa: Edições 70, 2011.

BERTH, J. Empoderamento. São Paulo: Sueli Carneiro; Pólen, 2019. (Feminismos Plurais)

BETELHEIM, B. A psicanálise dos contos de fadas. Rio de Janeiro: Paz e Terra, 1980.

BOJUNGA, L. A bolsa amarela. Rio de Janeiro: Casa Lygia Bojunga, 1976.

BOURDIEU, P. A dominação masculina. Rio de Janeiro: Bertrand Brasil, 2019.

BRENMAN, I. Até as princesas soltam pum. São Paulo: Brinque-Book, 2008.

BRENMAN, I. O que os meninos fazem? O que as meninas fazem? São Paulo: Callis Ed., 2009.

BUARQUE, C. Chapeuzinho Amarelo. Rio de Janeiro: Editora José Olympio, 2009.

BUTLER, J. Problemas de gênero: feminismo e subversão da identidade. Rio de Janeiro: Civilização Brasileira, 2019.

CAVALCANTE, R. B.; CALIXTO, P.; PINHEIRO, M. M. K. Análise de Conteúdo: considerações gerais, relações com a pergunta da pesquisa, possibilidades e limitações do método. Informação e Sociedade estudos. Paraíba, v. 24, n. 1, abr., 2014.

CARRANCA, A. Malala: a menina que queria ir para a escola. São Paulo: Companhia das letrinhas, 2015.

CARROLL, L. Alice: Aventuras de Alice no país das Maravilhas; Através do espelho e o que Alice encontrou por lá. Rio de Janeiro: Jorge Zahar, 2009.

CARYL, H. A princesa e as ervilhas. São Paulo: Brinque-Book, 2013.

COLASANTI, M. A moça tecelã. São Paulo: Global, 2004.

COLE, B. A princesa sabichona. São Paulo: Martins Fontes, 1998. 
FAVILLI, F.; CAVALLO, F. Histórias de ninar para garotas rebeldes: cem fábulas sobre mulheres extraordinárias. São Paulo: V\&R Editoras, 2017.

FAVILLI, F.; CAVALLO, F. Histórias de ninar para garotas rebeldes 2. São Paulo: V\&R Editoras, 2018.

FREIRE, P. Pedagogia do oprimido. Rio de Janeiro: Paz e Terra, 1970. 184 p.

FREIRE, P. Pedagogia da esperança: um reencontro com a Pedagogia do Oprimido. Rio de Janeiro: Paz e Terra, 1997.

HALL, S. A identidade cultural na Pós-modernidade. Trad. Tomaz Tadeu da Silva e Guacira Lopes Louro. Rio de Janeiro: DP\&A, 2005.

HOMEM, M. Coisa de menina? Uma conversa sobre gênero, sexualidade, maternidade e feminismo. São Paulo: Papirus 7 mares, 2019.

HOOKS, B. O feminismo é para todo mundo - políticas arrebatadoras. Rio de Janeiro: Rosa dos tempos, 2019.

HOOKS, B. Ensinando a transgredir - a educação como prática da liberdade. São Paulo: WMF Martins Fontes, 2017.

IGNOTOFSKY, R. As cientistas: 50 mulheres que mudaram o mundo. São Paulo: Blucher, 2017.

ISADORA, R. A princesa e a ervilha. São Paulo: Farol literário, 2010.

JOSÉ, E. As horrorosas maravilhosas. São Paulo: Difusão Cultural do Livro, 2008.

LAMOUR-CROCHET, C. A revolta das princesas. São Paulo: Saber e ler, 2013.

LEWIS, C. Aventuras de Alice no país das Maravilhas; Através do espelho e o que Alice encontrou por lá. Rio de Janeiro: Jorge Zahar Ed, 2010.

LINDGREN, A. Píppi Meialonga. São Paulo: Companhia das Letrinhas, 2001.

LOURO, G. L. Gênero, sexualidade e educação: uma perspectiva pós-estruturalista. Petrópolis, RJ: Vozes, 2011.

MACHADO, A. M. Histórias à brasileira - A donzela guerreira e outras. São Paulo: Claro Enigma, 2011.

MATTHEWS, E. Diferente como Chanel. São Paulo: Cosac Naify, 2009.

PANKHURST, K. Grandes mulheres que mudaram o mundo. São Paulo: Vergara e Riba Editoras, 2018.

PETIT, M. Os jovens e a leitura: uma nova perspectiva. São Paulo: Editora 34, 2008.

PIQUEMAL, M. Curiosa, Tagarela e Vaidosa. São Paulo: Editora Dedo de prosa, 2014.

PLANTEL, E. As mulheres e os homens. São Paulo: Boitempo, 2016.

REIS, N.; PINHO, R. Gêneros Não-Binários: Identidades, Expressões e Educação. Revista Reflexão e Ação, v. 24, n. 1, p. 7-25, 2016.

RIBEIRO, D. Lugar de fala. São Paulo: Sueli Carneiro; Pólen, 2019. (Feminismos Plurais)

ROCHA, R. Marcelo, marmelo, martelo. Rio de Janeiro: Salamandra, 1976. 60 p.

ROSEMBERG, F. A mulher na literatura infanto-juvenil: revisão e perspectivas. São Paulo: Fundação Carlos Chagas, 1975. 173 p. (Cadernos de pesquisa)

SCOTT, J. W. Gênero: uma categoria útil de análise histórica. Educação e Realidade, Porto Alegre, v. 20, n. 2, p. 71-99, jul./dez. 1990.

SKLIAR, C. A. A invenção e a exclusão da alteridade "deficiente” a partir dos significados da anormalidade. Educação e Realidade, Porto Alegre, v. 24, n.1, p. 15-32, jul./dez., 1999. 
SOLNIT, R. Os homens explicam tudo para mim. São Paulo: Cultrix, 2017.

SOUZA, D. P.; CARARO, A. Extraordinárias: mulheres que revolucionaram o Brasil. São Paulo: Seguinte, 2018.

SUPPA. E o príncipe foi para o brejo. São Paulo: Folia das letras, 2014.

TIBURI, M. Feminismo em comum: para todas, todes e todos. Rio de Janeiro: Rosa dos tempos, 2018.

VEIGA-NETO, A. Incluir para excluir. Proposições, Porto Alegre, v. 12, n. 2-3, p.35-36, mar., 2001. 